\title{
Analysis of Electricity Stealing and Research of Anti-stealing Measures
}

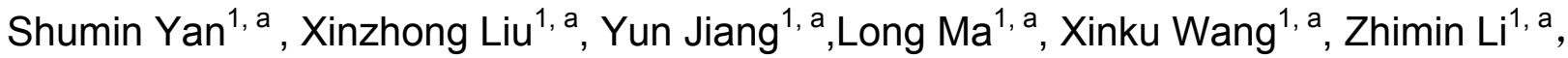 \\ JiaKun Lei ${ }^{1, a}$, Lizong Wang ${ }^{2, b}$,Chengzhe Dong ${ }^{2, b}$,Wenxin Han ${ }^{2, b}$ \\ ${ }^{1}$ Dezhou power supply company of Shandong Province, Dezhou, 253000, China \\ ${ }^{2}$ Beijing Xinyuan Green Energy Technology Co. Ltd,Baoding,071000, China \\ aemail: dzgdgsml@163.com, bemail: 47407349@qq.com
}

Keywords: Loss reduction; Anti-stealing simulation; remote monitoring and control

\begin{abstract}
The line loss is an important economic and technical index to evaluate electricity power enterprise production and management, according to the nature it can be divided into theoretical line loss and management line loss. Management line loss is caused by metering equipment error or by poor management. Currently, electricity stealing is becoming more high-tech,committing method more hidden, and renovating means more constant, which brings great difficulty to the work of anti-stealing. In that case,anti-stealing electricity situation is becoming more and more significant. In view of the above problems, this paper puts forward by analyzing the judgment and principle of the mainstream high-tech electricity stealing measures, summing up a set of practical and effective high-tech anti-stealing measures.Through the establishment of anti-stealing technology learning platform for research and practice and the completion of the intelligent remote anti-stealing simulation training base, improving the professional quality of the working staff. Building remote intelligent anti-theft warning platform, achieving the innovation and breakthrough of anti-stealing management.
\end{abstract}

\section{Introduction}

Power, as one of the important energy in China, continued to play an important role in the development of the economy. Reducing the line loss rate is an important measure to increase energy utilization. The significant reason of the line loss is the high-tech electricity stealing growing seriously, further exacerbating the high power network line loss ${ }^{[1]}$.

In Europe ,United States and other developed countries, the electricity stealing phenomenon is widespread, and along with progress of science and technology, anti-stealing measures develop continuously. In America, for example, California's largest power company in the United States, the Pacific gas and electric power company in June 2001 announced that due to the country is faced with serious power crisis, the California's electricity stealing phenomenon is astonishing .According to the power company, the former executive Howard Dean response to the press, said the loss of economy of the company was between $\$ 100$ million to $\$ 400$ million each year because of the electricity stealing.Howard dean also said that the United States national electricity stealing problems, the economic loss caused by electricity stealing is as much as $\$ 4$ billion every year ${ }^{[2]}$.

With the development of technology and method which is used for preventing people from stealing electricity,the method of stealing electricity are also improving. Above all, the problem of preventing stealing electricity is an eternal topic. It need professionals' continuous research and people's much more study.

The paper begins from analysis the principle of electricity stealing, a variety of methods of electricity stealing are presented, such as high frequency, strong magnet, remote control and so on. 
Then discuss high-tech anti-stealing measures ${ }^{[3]}$. Only by making full use of modern computer technology and software technology and modern communication technology with real-time data exchange ability can we prevent the electricity stealing behaviors ${ }^{[4]}$. In conclusion, the reduction of electricity loss and electricity management still have a long way to go.

\section{Principle analysis of electricity stealing}

Here are several methods and principle of common,conceal and high-tech electricity stealing.

\subsection{High frequency electricity stealing}

High frequency electricity stealing is the use of high power high frequency interference sources (the high power signal generator signal strength is as high as $680 \mathrm{~V} / \mathrm{m}$, is 68 times of the national standard), the main equipment is closer from the metering device in the house. When the $220 \mathrm{~V}$ power supply is connected, placing the antenna signal box next to the table, using the high frequency pulse interference electric meter chips directly, under the condition of strong interference, metering chip is reset or in the crash state, can not measure normally.

Currently, smart meters have been adopted with smart metering chips. Three-phase four-wire and three-phase three-wire smart meters, or single-phase residential ladder electricity meters are all faced with the same interference problem ${ }^{[5]}$.

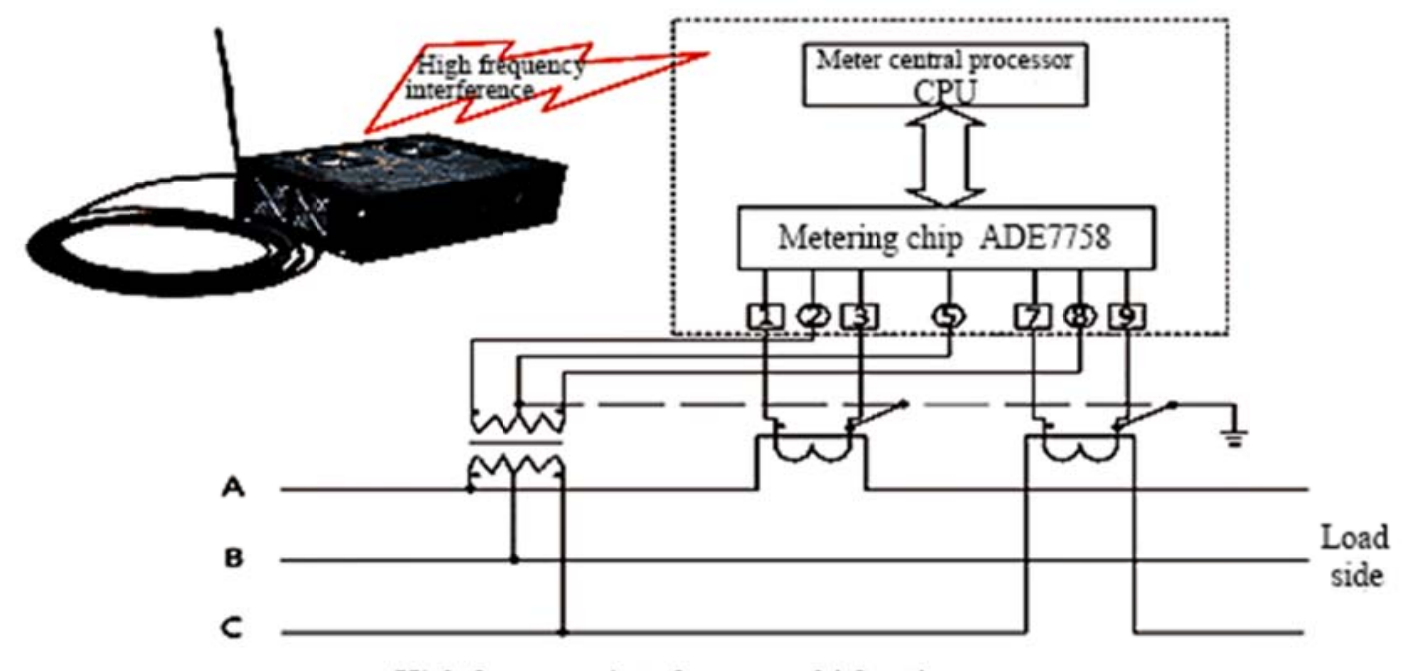

High frequency interference multi function meter

Fig.1. High frequency interference multi-functional electric meter

\subsection{Strong magnet electricity stealing}

Meters with the sampling CT core has high weak magnetic field permeability, saturated magnetic induction intensity is generally between $0.6-1.0 \mathrm{~T}$.

Strong magnet's magnetic induction intensity is much greater than 1T. Placing a strong magnet behind the box of meter, making the CT magnetic saturation by changing the magnetic field intensity inside the meter, reducing measuring electric current and achieving the goal of electricity stealing with little damage to the seal ${ }^{[6]}$.

The meter shown in fig.2 is a three-phase four-wire smart meter, operating normally. Affected by strong magnets, current value changed from 5.50A to $0.30 \mathrm{~A}$, and the power loss is about $94 \%$. 

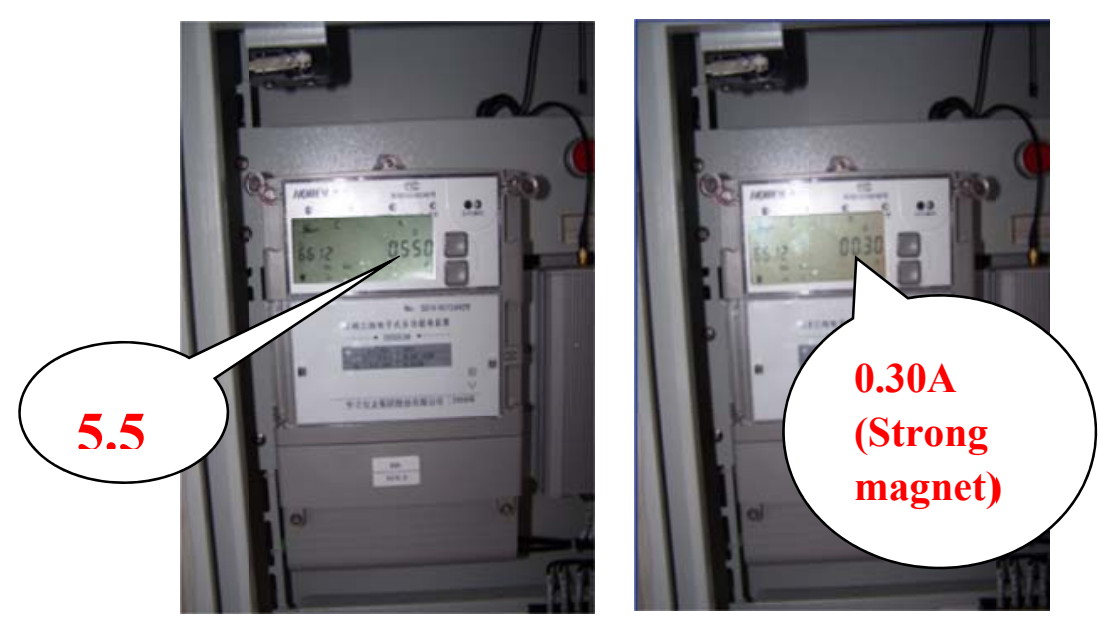

Fig.2. Experimental demonstration of strong magnet electricity stealing

\subsection{Remote controls electricity stealing}

One of the most common methods of remote controls is installing a wireless receiver and used in series with voltage circuit or current circuit in the meters. Using remote control command voltage circuit, current circuit externally and making it on or off according to the instructions, cause shunt or under voltage ${ }^{[7]}$.

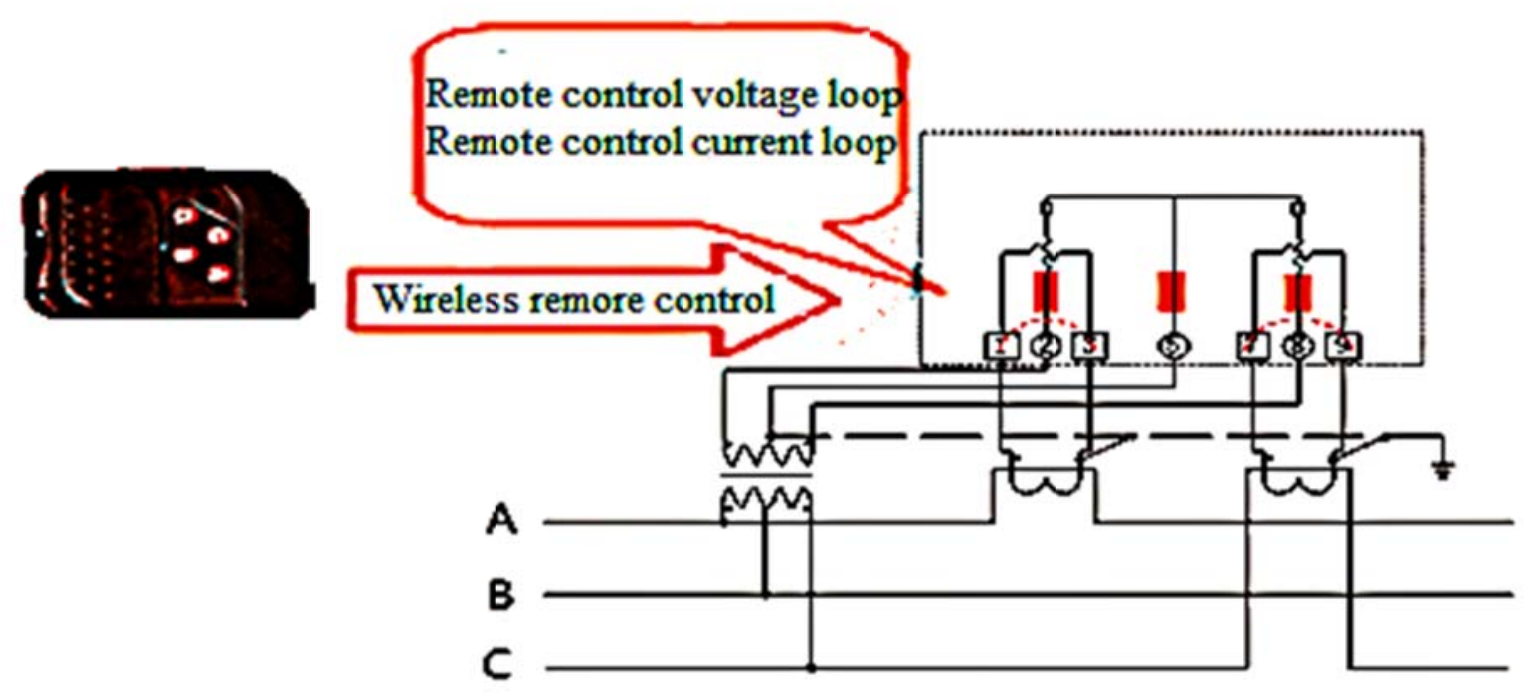

\section{The meter with remote control mode of internal electric larceny}

Fig.3. Principle of remote controls electricity stealing

\subsection{Terminal box electricity stealing}

In measurement system, the current circuit can not only open but also in parallel, it can only access various measuring devices in series. Terminal box shunt after the second cable access to the terminal box, Making current incoming line and outgoing line short-circuit.Parallel connection at the current potion in terminal box lead to part of the current doesn't pass through measuring device, loss ratio is related to the resistance ratio of electric meter circuit and the negative control loop.

\subsection{Fault phase electricity stealing}

Using a variety of methods changes the normal connection of watt-hour meter, or accessing voltage and current which has no electricity contact with watt-hour meter coil intentionally. In addition, the use of specific inductor or capacitor connection, so as to change the watt-hour meter normal phase relationship between voltage and current in coil and make the watt-hour meter slow or even reverse. That is called fault phase electricity stealing. 


\subsection{Under voltage electricity stealing}

Using a variety of methods changes the voltage circuit normal connection of electricity measurement deliberately, or causing voltage circuit inside the meter under voltage or voltage reduce, resulting in the metering energy is less than the real consumed energy. This method is called under voltage electricity stealing.

\section{Anti-stealing measures and simulation laboratory}

\subsection{High frequency anti-stealing}

1. Installing the anti-stealing meter box

Using anti-stealing meter box to prevent high frequency interference meters. Special protection processing has been made inside the box, if there is a high frequency signal intrusion, the box will isolate the signal, block the signal outside the box, so that high-frequency cannot interfere with the meter.

2. Installing inspection instrument and electric energy data acquisition system

Installing inspection instrument can collect real-time data from meter, then send it to electric energy data acquisition system through GPRS. Users can monitor meter's operation on-line through electric energy data acquisition system ${ }^{[8]}$.

3. Strengthen the training work to prevent high frequency interference

Practice skillfully and use all kinds of high-tech anti-stealing equipment.Increase inspectors' anti-stealing experience through case.

\subsection{Strong magnet anti-stealing}

\section{Change the meter box's structure}

Try to change the meter box's structure, such as thickening box thickness, increasing distance between meter and the box, changing box's material, etc.

But the strong magnet used by electricity stealer is made by rare earth materials, its magnetic force is about 50 times larger than the traditional magnet, the greater the volume, the stronger the magnetism.Even change the distance between magnet and electric meter, interference significantly reduced, as long as there is strong magnet, the interference is not disappeared, power is still missing. 2. Strengthen the magnetic shielding of transformer and meter.

On account of stainless steel not magnetic conductive, a layer of magnetic conductive iron should be put in stainless steel metering box, so that most of the magnetic field can be shielded.

3. Set a back support at the back of meter inside the metering box to reduce the magnetic field effect.

Experiments show that when the distances between magnet from meter is greater than $20 \mathrm{~cm}$, impact can be in the error range.

4. Install the strong magnetic cavity behind the meter.

In the magnetic field, because the magnet material permeability is thousands of times bigger than the air permeability, so magnetic resistance in the cavity is much bigger than that of ferromagnetic materials. Most part of the external magnetic field's magnetic induction line will go through the wall of ferromagnetic materials, very little go into the cavity, so as to achieve the purpose of the static magnetic shielding. Anti professional stealing prepaid box chooses permalloy materials which is high permeability, by using the principle of the zero gauss cavity, the box has achieved "static magnetic vacuum", so it can prevent the strong magnet electricity stealing. 


\subsection{Remote control anti-stealing}

1. The use of new equipment, anti-stealing meter box, with identification function, special identity key. It will send out alarm information, if it is not the staff who open the door.The camera of inspection instrument can sense the human body's infrared and camera automatically to obtain evidence, and send the alarm information.

2. Installing inspection instrument and electric energy data acquisition system

Installing inspection instrument can collect real-time data from meter, then send it to electric energy data acquisition system through GPRS. Users can monitor meter's operation on-line through electric energy data acquisition system.

3. Strengthen the training work to prevent high frequency interference

Practice skillfully and use all kinds of high-tech anti-stealing equipment.Increase inspectors' anti-stealing experience through case.

\subsection{Anti-stealing screening measures}

1. Collecting primary current, current before the mater, comparing with meter current, if the primary current and current before meter is equal, both greater than the meter current, it means shunt happened inside the meter and alarm information will be send out.

2. Taking $10 \mathrm{kV}$ side primary current, current before and after terminal box,as well as meter current, then making analysis and comparison. Finding the position of electricity stealing, control proof of shunt terminal box electricity stealing.

3. Remote monitoring the $10 \mathrm{kV}$ current and the secondary side current of high voltage metering box.

\subsection{Anti-stealing simulation laboratory}

Laboratory is mainly composed of electricity stealing and anti-stealing simulation screen and anti-stealing remote inspection monitoring system software, anti-stealing remote inspection device installed at the client side, high voltage wireless transformer, precision power source and so on.

Using remote anti-stealing inspection method, voltage dividing (under voltage), shunt, phase shift, remote control, strong magnet interference, high frequency interference and other typical examples of electricity stealing as the foundation. Combining theory and practice, covering the typical electricity stealing and high-tech simulation experiment. Integrating anti-stealing technology research, training, learning, theoretical verification, practical skills, inspection identification together.

Equipment configuration is currently the leader in the country. On the one hand, carry out anti-stealing and against default electricity utilization research and technical research, enhance anti-stealing technology content, solve the difficulties of anti-stealing investigation and evidence collection.On the other hand, by simulating different kinds of typical power metering device, strengthen training to improve professional skills of electrical inspectors.

The laboratory is composed of four simulation screens, four display screen and general control instructor computer.

Each simulation screen is equipped with a computer, it can be set as two modes local and network. As for local mode, real-time data and trainees' operations will be displayed on the screen. When it comes to network model, the data and operations will send to instructor computer through the network, instructor can control operation situation of each group of students in real time, and display it on the big screen through the projector . 


\section{Remote intelligent precautionary Anti-stealing electricity monitoring platform}

The core technology of the monitoring platform is high-tension measurement and line loss analysis. It can detect and investigate multifarious power theft and recoup the losses of the enterprise.

The platform focus on the all-round monitoring of $10 \mathrm{kV}$ power distribution network and transformer electric meter. A platform serving the marketing analysis system is gradually established. It can provide data support for marketing and production department. Furthermore, problems like dispersive electricity stealing residents amount and high audit cost of investigation can building solved and the screening area can be reduced effectively and the precision of power check can be also improved greatly .

\subsection{The working principle of the monitoring platform}

Load monitor monitors the communal meter box of residents by treating individual meter box as a whole unit. Load monitor is installed in the power supply side of the watt-hour meter box, the the total power consumption in the power supply side of the power meter box can be collected and measured. In addition, the information of each watt-hour meter in the electric meter box are monitored at the same time. Finally, the two types of data will be uploaded to master station of the monitoring system through wireless channel. Master station will summarize and analyze the two types of the data from the electric meter box and make a judgement whether there is power theft of the user and issue a report to the police if there is power theft. Therefore, the consumption behavior of every user can be confirmed.

\subsection{The system structure of the monitoring platform}

\subsubsection{The composition of the monitoring platform}

Wireless high-voltage current acquisition device and wireless receiving module are installed and the actual load of users in high side can be acquired through the information transmission channel of the load control system. The data at the secondary side of the user can be read through the smart power inspection master station system and the interface of the load control system data server and the decision whether there is power theft and to report the police can be made.

\subsubsection{The structure of the monitoring platform}

1) Online monitoring instrument of line loss: Iinstalled in the $10 \mathrm{kV}$ or $35 \mathrm{kV}$ lines segments selected in advance, the actual load of the line can be real-time monitored, and the data can be sent to the intelligent remote anti-stealing electricity monitoring platform timely.

2) Remote power inspection instrument: Installed in the measurement circuit of the user, 24 hours real-time monitoring the user's electricity situation, the actual load of every segment in measuring circuit can be monitored remotely, monitoring internal parameters and running status of the electric meter, monitoring internal magnetic field intensity and the high frequency signal strength of the meter box, and all the data will be sent to the intelligent remote real-time anti-stealing electricity monitoring platform. If there is any abnormal electricity, it can report to the responsible person of the mobile phone automatically. Therefore, the responsible person can monitor his electricity consumption situation at any time and any place.

3) Remote intelligent anti-stealing electricity monitoring platform: Analyze the data uploaded by the devices installed on the line timely, achieve all-round monitoring of the whole line through intelligent identification and intelligent positioning.

\subsection{The scheme of the monitoring platform}

1) Lines can be divided into $3 \sim 10$ sections based on the number of users and the network structure of the high loss lines. Install online monitoring instrument of line loss in line segment node to monitor segmented load data of the $10 \mathrm{kV}$ lines and transmit the data to the host system. 
Afterwards, the branch with high line loss can be confirmed quickly by analyzing the load data of the users with special transformer collected by the load control system. Principle is as follows:

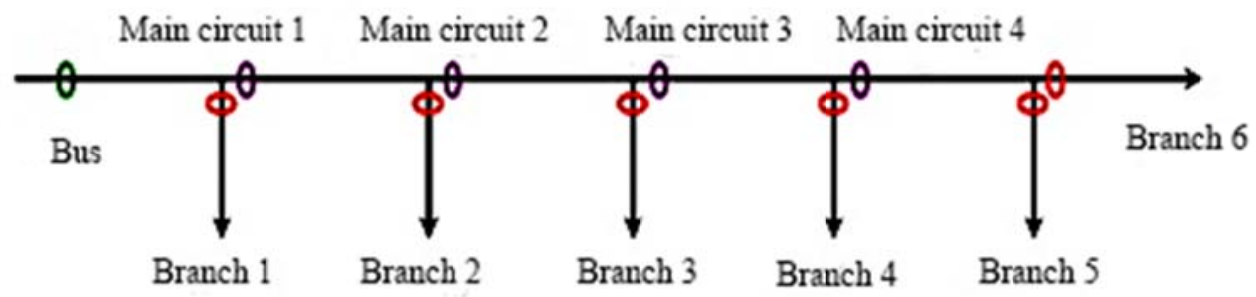

Fig.4. Principle of installing online monitoring platform

Considering the security and secrecy of the investigation of electricity stealing, the online monitoring instrument is open-type and can be removed and installed electriferously. Branch load is the equivalent of its scheming load under normal situation.

2) After establishing the high loss branch, we treat the key user with one-on-one way to install electricity remote inspection instrument and conduct 24-hour remote monitoring to the users in the abnormal area. Therefore, the precision positioning of the way and the palce of electricity stealing can be realized.

3) The reduction of line loss in the whole line can be realized by the specific rectification to the key users at the branch with high line loss.

\subsection{The function of the monitoring platform}

\subsubsection{Real-time data acquisition}

1) Collecting the information of the switch and the operation parameters in $10 \mathrm{kV}$ line independently.

2) Collecting the state parameters of the distribution transformers separately.

3) Collecting the power, electric quantity and frequency of the power grid.

\subsubsection{Remote meter reading}

We can read the public transformers and classified meter remotely by read multi-function digital meter through 485 interface. We can also observe and record electricity parameters timely by using pulsing meter reading module and send them to the control terminal through communication module.

\subsubsection{Load control}

We control the user directly, including time-phased power and electric quantity control. Operating individual even entire terminal and set each terminal in control time rounds during operating. We can increase or delete electricity-limit project and change or remove it. Furthermore, electric-protect measurement can be conducted to important users or remove some users from a group of users to ensure them do not participate in the set of operations. Resetting the terminal can also be realized, including the initialization of hardware, parameter area and data area. The effect of electricity limiting can be collected through the terminal after electricity limiting operation. Time-limit talk and sending messages to the terminal can be realized. Master station can broadcast to the terminal everyday (can set at any time), in order to prevent data inaccuracy resulting from the clock error.

\subsubsection{Line loss statistics}

We can calculate the losses in every line and substation on difference line and different voltage. The losses in every branch and point can be statisticed by time and representerd by graph. 


\subsubsection{Analysis of electricity stealing}

The Load capacity curve of every monitoring point, line and gateway can be calculated and gathered by using the analysis function of the computing center through monitoring various intelligent collecting terminal. Electricity stealing can be prevented effectively by tracking abnormal electric consumption at every point and recording power theft.

\section{Conclusion}

As the improvement of anti-stealing electricity technology and measurement, power theft also continue to improve, so the problem about anti-stealing electricity is a everlasting topic. In an increasingly tense situation of electricity demand, the reduction of electricity loss and electricity management have a long way to go. The work of preventing electricity-stolen is a long-term and arduous task in current economic conditions. Practice has proved that adopting one-to-one prevention measurement passively is useless if we want to against effectively to various ways to steal electricity emerging in endlessly. We must adopt measures with high-tech to prevent power theft and make full use of modern computer technology and software technology which is of super strong data analysis ability and modern communication technology which is of the real-time data exchange ability. Only then can we effectively curb the phenomenon of power theft.

\section{References}

[1] Yang J, Wang G. Leak detection and location methods for gas transport pipelines[J].Control and Instruments In Chemical Industry, 2004, 31: 1-5

[2] LI D, WANG Y, LI C, et al. A design of an box-opening recorder for anti-power-stealing based on RFID [J]. Electrical Measurement \& Instrumentation,2008,10:014

[3] Lan Y. Electricity Larceny Prevention in DMS[J]. Electric Power Automation Equipment, 2002, 22(1): 84-85.

[4] HU L, YAN Y, HUANG J, et al. Research on new real-time systemic anti-electrcity filching system [J][J]. Power Demand Side Management, 2006, 2: 008.

[5] QIN C, ZHAO J, Zhang L, et al. Analyzing and Modeling for Shunt Current Electric Larceny of Electric Power Metering System[J]. Electrical Measurement \& Instrumentation, 2009, 2: 013.

[6] HAO J, YIN W, SUN C. Design of Three Phase Multi-function and Stealing Power Preventing Watt-hour Meter Based on ATT7022B [J][J]. Journal of Northeast Dianli University, 2007, 1: 010.

[7] Gu-jinga HAN, Xiao-gonga YIN, Lianga QIN, et al. A novel technique of preventing electricity-stealing in current method for electric power measuring equipment $[\mathrm{J}][\mathrm{J}]$. Electrical Measurement \& Instrumentation, 2007, 10: 119-123.

[8] SUN F, LIU Z, ZHANG Y. Research on electricity anti-stealing system based on GPRS wireless communication [J]. Telecommunications for Electric Power System, 2007, 1: 013. 